\title{
Labor Market Integration and Its Effect on Child Labor
}

\section{Manfred Gärtner}

\begin{abstract}
This note demonstrates that when developing countries remove barriers to migration and integrate their labor markets, children may be driven out of schools and into informal or paid employment in the comparatively rich countries. In industrialized countries, the same mechanism might drive families into social security or government-subsidized jobs.
\end{abstract}

Keywords Labor market · Migration · Integration · Child labor· Subsistence

JEL J13 $\cdot$ O15

\section{Introduction}

The issues of child labor, its causes and potential remedies have received considerable attention in academia and features prominently in the policy papers of pertinent institutions such as the United Nations and the World Bank. ${ }^{1}$ This note looks at how international labor market integration affects child labor. The proposed framework for the analysis is a two-country version of the basic model proposed in the seminal paper by Basu and Van (1998) which has been quite influential in the academic discussion of the economics of child labor and of related policies.

\footnotetext{
${ }^{1}$ For a general survey covering the wide spectrum of issues related to child labor, see Edmonds (2008). A narrower account of theoretical and empirical work on the economics of child labor is provided by Basu (1999).

M. Gärtner $(\bowtie)$

Institute of Economics, School of Economics and Political Science, University of St. Gallen,

Bodanstrasse 1,

9000 St. Gallen, Switzerland

e-mail: manfred.gaertner@unisg.ch
} 


\section{The Model and the Closed-Economy Equilibrium}

The backbone of the Basu and Van model is provided by two axioms:

The Luxury Axiom A family will send children only to work if the family's income would otherwise drop below subsistence levels.

Worker families derive income from work alone. They do not save and, hence, do not possess any wealth. Returns to capital may be thought to go to a capitalist class or to foreign nationals who own the entire capital stock.

The Substitution Axiom From the perspective of firms, adult labor and child labor are substitutes.

There are two countries 1 and 2. Both countries are poor in the sense that the risk of labor incomes to fall below subsistence levels is a possibility, if not a reality. Each country comprises $N_{i}$ families, and each family comprises $n_{i} \geq 2$ members, including one adult and one child who could work. Other family members are either too old or too young for paid work. Subsistence consumption per capita $s_{i}$ may differ between countries. Adults and children either work or they do not work.

In each country there are $m_{i}$ identical firms, which we aggregate to obtain a measure of one, producing $x_{i}$ units of a single consumption good. The demand for labor in each country is derived from the two production functions:

$$
x_{i}=T_{i} f\left(A_{i}+\alpha_{i} C_{i}\right)
$$

where $f(\cdot)$ is country $i$ 's well-behaved production function, $A$ and $C$ denote the aggregate number of employed adults and children, respectively, and $\alpha \leq 1$ is a parameter that measures the productivity of children relative to adults. If the number of firms is sufficiently large to make them wage takers and children's wages reflect their productivity relative to adults, firms maximize profits given by:

$$
\pi_{i}=T_{i} f\left(A_{i}+\alpha_{i} C_{i}\right)-w_{i}\left(A_{i}+\alpha_{i} C_{i}\right)
$$

which yields an adult wage rate of $w_{i}=T_{i} f^{\prime}(\cdot)$. The wage rate for children reflects their productivity deficit and is: $w_{C, i}=\alpha_{i} T_{i} f^{\prime}(\cdot)=\alpha_{i} w_{i}$.

Given the number and composition of families, and since the adult wage rate must not fall below $n_{i} s_{i}$, which is the subsistence income required by the family, the supply of effective labor $S_{i}$ is:

$$
S_{i}\left(w_{i}\right)= \begin{cases}N_{i} & \text { if } w_{i} \geq n_{i} s_{i} \\ \left(1+\alpha_{i}\right) N_{i} & \text { if } w_{i}<n_{i} s_{i}\end{cases}
$$

Depending on the position of the demand for labor schedule derived from the maximization of Equation 2, and given the stepwise labor supply curve described by Equation 3, each country's labor market features two stable equilibria: a good equilibrium in which the adult wage is high enough to support the family without child labor, a bad equilibrium in which families cannot survive without the added income derived from child labor, or both. 


\section{The Two-Country Model with an Integrated Labor Market}

Suppose workers in country 1 are more productive than in country 2, perhaps because of a higher capital stock, better production technology, a superior infrastructure, or a climate that favors agricultural or aquacultural production. Then $w_{1}>w_{2}$ when both countries are in the same type of equilibrium, i.e.; with or without child labor.

Next, assume that countries 1 and 2 open their borders for foreign workers to create an integrated labor market. The employment decision of workers is described by The Mobility Axiom Workers prefer to work in their home country where their family lives. They emigrate to work abroad only if the foreign wage rate exceeds the domestic wage rate.

Suppose child labor had been eradicated in both countries. Then both countries start from their good labor market equilibrium, so that country 1 pays a higher wage rate, as noted above. Then the mobility axiom predicts effective labor in country 1 to be provided in the form of a stepwise, belly-shaped labor supply curve given by:

$$
S_{1}\left(w_{1}\right)= \begin{cases}N_{1}+\beta_{2} N_{2} & \text { if } w_{1} \geq n_{i} s_{1} \\ N_{1}+\alpha_{1} N_{1}+\beta_{2} N_{2} & \text { if } w_{2}<w_{1}<n_{i} s_{1} \\ N_{1}+\alpha_{1} N_{1} & \text { if } w_{1}<w_{2}{ }^{\prime}\end{cases}
$$

The consequences for wage rates and employment that result from the removal of migration barriers and the integration of the two labor markets into one are conveyed by two propositions:

Proposition 1 When labor is more productive in one of two countries and no bad equilibrium with child labor exists in either country as long as labor markets remain isolated, the integration of labor markets may create a bad equilibrium with child labor in the country with initially higher wage rates.

\section{Proof. See Appendix A}

The emergence of child labor is avoidable, though, because a good equilibrium without child labor may continue to exist, and both equilibriums would be locally stable.

Proposition 2 When labor market integration generates a bad equilibrium with child labor in the country that featured higher wage rates without migration, this equilibrium may be unique in the sense that the good equilibrium has disappeared.

\section{Proof. See Appendix A}

This proposition strengthens the possibility described by Proposition 1 in the sense that the equilibrium with child labor may be unavoidable because it could be universally stable.

\section{Intuition and Graphical Illustration}

Figure 1 illustrates the effects suggested by propositions 1 and 2 and may provide some intuition. Postulated parameter settings that keep the graph less cluttered are $s_{1}=0$ and $\alpha_{1}=1$. 


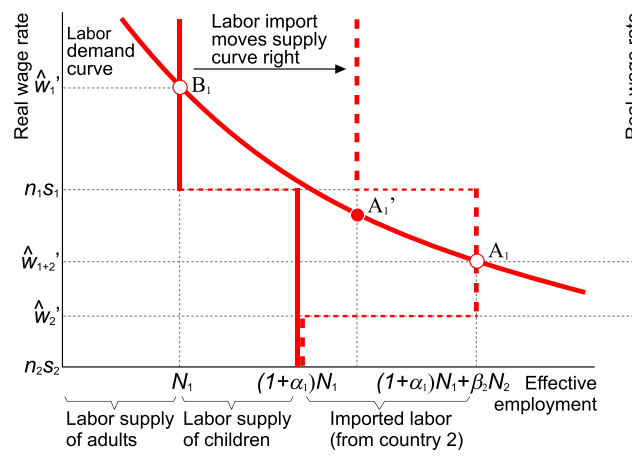

Country 1 (poor)

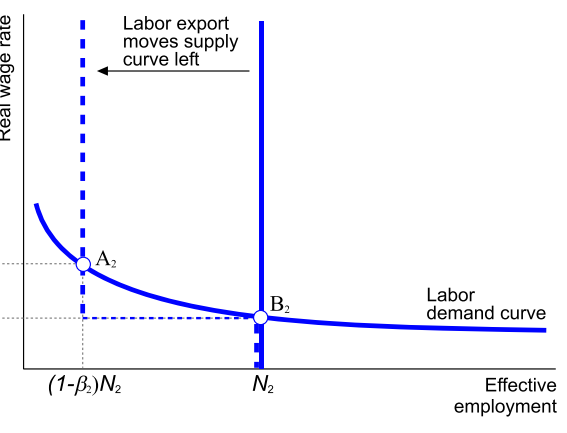

Country 2 (very poor)

Fig. 1 How labor market integration may generate child labor in a two-country version of the Basu and Van (1998) model

As long as labor markets are separated, labor market equilibriums are $\mathrm{B}_{1}$ and $\mathrm{B}_{2}$, respectively, where the solid vertical labor supply curves intersect the country's labor demand curve. Only adults work since wage rates exceed subsistence needs in both countries. There is a step in the labor demand curve at subsistence income $n_{i} s_{i}$, where families are compelled to send their children to work, though this step has vanished in the poorer of the two countries because the graph lets subsistence income equal zero. The graph is drawn to generate a unique equilibrium in each country, though multiple equilibriums are possible when labor markets are separated, as well.

When borders are opened for migrant or guest workers, adult workers move from country 2 to country 1 because of the higher wage rate, as postulated by the mobility axiom. This moves the labor supply curves into their dashed positions. Country 2 moves to the left, pushing its wage rate up, and country 1 it increases the labor supply by the same amount, driving its wage rate down. Migration continues until the two countries' wage rates have converged. By then, some 75 percent of country 2's adults have migrated and the wage rate is: $\widehat{w}_{1+2}$. Since this influx of foreign adults alone would have driven country 1 's labor market into point $\mathrm{A}_{1}$ ' and thus the wage rate below subsistence needs, this new equilibrium features child labor in line with the luxury axiom. The second step in country 1 's new labor supply curve that occurs at $\widehat{w}_{2}$, where foreign workers would decide to return home, does not come into play in the case depicted here.

\section{Refinements}

The above analysis employed several assumptions that served to keep the argument parsimonious and transparent, but are not strictly needed for the demonstrated result.

One of these assumptions was that worker families do not own any wealth. As Swinnerton and Rogers (1999) show, policies that redistribute the capital stock towards workers may indeed eradicate child labor once a sufficient fraction of workers participate in the returns generated by capital. As long as this fraction remains below this threshold, however, a bad equilibrium with child labor continues to loom as a possibility and the results derived above remain valid.

Another assumption is that workers migrate abroad as soon as foreign wage rates exceed domestic ones. This assumption may certainly be relaxed in favor of assuming 
some absolute or relative threshold. Qualitative results would not be affected, but the convergence of wage rates would stop before full equalization is achieved.

It is also assumed that, even after country 2's workers have migrated, labor supply decisions are still based on country 2's subsistence income, despite the fact that one family member lives abroad and faces higher living costs. This may be relaxed in favor of letting the family's subsistence income be a weighted average, i.e. $\left[s_{1}+(n-1) s_{2}\right] / n$. This does not differ much from our treatment when the family is large. If it matters, it is not likely to affect the above propositions.

Finally, the labor supply decisions in the basic Basu and Van (1998) model are discontinuous. But when individuals may supply any amount of labor, the labor supply curve may become Z shaped as in Dessing (2002), or if the labor supply curve switches from a strict stepwise shape to one where the employment of children kicks in gradually, as in the general model sketched in Basu and Van (1998), there is again no obvious reason why this would affect the nature of our results. ${ }^{2}$

\section{Summary and Conclusions}

By employing the basic model proposed by Basu and Van (1998) and extending it to a two-country version, this note looked at how the opening of borders for foreign workers affects labor markets in developing countries. The two countries are assumed to differ in labor productivity and to feature closed-economy labor market equilibriums in which children do not work. The result is that when barriers to migration are removed in favor of labor market integration, this may generate child labor in the richer of the two countries. While this has been shown to apply in a formal model with rather strict assumptions, it should be robust to quite a number of generalizations. Also, child labor may be considered a stand-in for other expansions of the supply of labor beyond its normal level, such as the holding of multiple jobs, forcing workers into social security because jobs at their skill level do not support families any longer, or the emergence of a government-subsidized new segment of the job market. Thus, the results and risks laid out here should not only be noted when studying developing countries, but also when looking at the opening and integration of labor markets between heterogeneous industrial countries.

\section{Appendix A}

\section{Proof of Proposition 1}

Proof. Good initial equilibria with separated labor markets imply:

$$
\widehat{w}_{1}=T_{1} f^{\prime}\left(N_{1}\right)>\widehat{w}_{2}=T_{2} f^{\prime}\left(N_{2}\right)
$$

as well as:

$$
T_{1} f^{\prime}\left[\left(1+\alpha_{1}\right) N_{1}\right]>n_{1} s_{1}
$$

\footnotetext{
${ }^{2}$ However, see Gärtner and Gärtner (2011) for a discussion of sufficient conditions for the emergence of multiple equilibria in the labor market when the labor supply curve is outward-sloping.
} 
and:

$$
T_{2} f^{\prime}\left[\left(1+\alpha_{2}\right) N_{2}\right]>n_{2} s_{2} .
$$

The proposition claims that after labor markets became integrated, an equilibrium is feasible in which:

$$
n_{1} s_{1}>T_{1} f^{\prime}\left[\left(1+\alpha_{1}\right) N_{1}+\beta_{2} N_{2}\right]=T_{2} f^{\prime}\left[\left(1-\beta_{2}\right) N_{2}\right]>n_{2} s_{2}
$$

The inequality given on the right-hand side of Eq. A3 follows from Eq. A2 and $f^{\prime \prime}(\cdot)<0$.

The inequality given on the left-hand side may hold, given that both sides are determined by independent parameters and $f^{\prime \prime}(\cdot)<0$, which means that $f^{\prime}(\cdot)$ approaches 0 when $\beta_{2} N_{2}$ becomes very large.

\section{Proof of Proposition 2}

Proof. The post-integration equilibrium with child labor is unique if:

$$
n_{1} s_{1}>T_{1} f^{\prime}\left(N_{1}+\beta_{2} N_{2}\right)
$$

which again is always possible because both sides are determined by independent parameters and, given $f^{\prime \prime}(\cdot)<0$, it becomes more likely, the larger $\beta_{2} N_{2}$.

\section{References}

Basu, K., \& Van, P. H. (1998). The economics of child labor. The American Economic Review, 88(3), 412-427. Basu, K. (1999). Child labor: cause, consequence, and cure, with remarks on international labor standards. Journal of Economic Literature, 37(3), 1083-1119.

Dessing, M. (2002). Labor supply, the family and poverty: the S-shaped labor supply curve. Journal of Economic Behavior \& Organization, 49(4), 433-458.

Edmonds, E. V. (2008). Child labor. Handbook of Development Economics, Elsevier, 3607-3709.

Gärtner, D., \& Gärtner, M. (2011). Wage traps as a cause of illiteracy, child labor and extreme poverty. Research in Economics. doi:10.1016/j.rie.2010.10.003.

Swinnerton, K. A., \& Rogers, C. A. (1999). The economics of child labor: comment. The American Economic Review, 89(5), 1382-1385. 